\title{
Lumbo-Sacral Angle Evaluation Among Lebanese Population
}

\author{
Khawli Loubaba, Haidar Hassan Khodor, and Kheir Eddine Hassane
}

\section{ABSTRACT}

Background: Lumbar lordosis is an essential postural element that has gained the interest of both clinicians and researchers for several years. It is the inward curvature made by the wedging of the vertebrae of the lumbar spine. Since there is paucity of data on the lumbar lordosis in the Lebanese population, most of the data used in clinical practice to classify hypo- and hyper-lordosis are based on studies from other races.

Aim: To identify the normal LSA in a Lebanese population, then see if there is a difference between the races and determine if this angle is affected by the gender or age.

Methods: A retrospective study established to measure lumbar lordosis using LSA technique. Lateral supine lumbosacral radiographs of 128 Lebanese subjects, aged between 19 and 84 years, were analyzed. Statistical analysis was done using SPSS version 20.0 .

Results: The mean value (SD) of LSA was $38.980(+9.90)$ with a min 15.70 and max 64.20. A significant difference was found between LSA and gender. However, there was no significant variation between this angle and age.

Conclusion: The mean value of this angle $38.980(+9.90)$ may form a reference for the Lebanese population. The study demonstrated that lumbar lordosis is affected by race and gender, with females having a greater LSA than males. Whereas the latter was not affected by age.

Keywords: Lumbar lordosis, Lebanese population, lumbosacral angle, radiography.

\section{INTRODUCTION}

Lumbar lordosis is an essential postural element that has gained the interest of both clinicians and researchers for several years. It is the inward curvature made by the wedging of the vertebrae of the lumbar spine [1]. Since it plays an important role in the weight-bearing of the entire upper part, abnormal changes in this curve leads to occurrence of low back pain or functional impairments [2].

Low back pain (LBP) is the $5^{\text {th }}$ most common cause for doctor visits; approximately $60-80 \%$ of people suffer from LBP through their lifetime [3], [4]. The relationship between lumbar lordosis and low back pain has a huge clinical importance since it acts as the base of therapeutic exercises for low back pain treatment and prevention [5].

Many techniques have been utilized to evaluate lumbar angles, including goniometry, radiography, flexible rulers, software methods, spinal mouse, and inclinometers. Among all these techniques, radiography remains as the golden standard method for the evaluation of these angles [6]. Many radiologic methods have been used to evaluate the lordosis angle on two-dimensional radiographs such as lumbosacral angle (LSA), tangential radiologic assessment of lumbar lordosis (TRALL), Cobb's angle and lumbar lordosis angle (LLA) [7].

Considering the treatment, the main target is to put the body in a physiologic position; so, it can keep its balance with minimal effort. The treatment might be non-operative or operative. The first one uses bracing to maintain the structural support or physiotherapy to strengthen the muscles. The second one includes various levels of invasive procedures or bony removal to realign the spine [8].

According to the literatures, several factors influence the angle of lumbar lordosis such as ethnicity, age, gender, obesity, posture, activity, muscular strength and flexibility of the spine and lower limbs; making it hard to know the optimal range of this angle [1], [2].

The majority of studies concerning the effect of age on the spine show that lumbar lordosis decreases or stays constant with ageing; just few have shown an increase in the latter. Studies examining gender differences in lumbar lordosis show that it is slightly larger in women or there is no significant dependency on gender. However, some of these studies, where age and sex were examined, were limited in sample size, and did not distinguish between men and women and subjects with or without back pain [9]. 
It is well known that good assessment led to good plan of treatment; that's why it is important to assess the lumbar lordosis in order to plan for a good treatment. There is paucity of data on values of lumbar lordosis angle in the Lebanese population; accordingly, values that represent hypo/hyper lordosis in clinical practice are established on studies from other races.

The first aim of this study is to identify the mean value of LSA in the Lebanese population, which may form a reference value for physicians, physiotherapists, and researchers in Lebanon.

The second aim is to compare the mean values obtained in this current study with other studies and determine if there's difference between the races.

The third aim is to identify if the LSA is affected by the gender or age.

Additionally, the measurement of these angles may be helpful first, in recognizing persons at risk of developing LBP as well as in the design of spinal instrumentations and implants that are specific for the population.

\section{MATERIALS AND METHODS}

In this chapter we aim to describe several methodological steps used to filtrate the data, evaluate the radiographic images using LSA method and finally using T-test and ANOVA to analyze the data obtained then compare it with other results.

\section{A. Design and Participants}

This study is a retrospective study established to measure LSA using 152 radiographs of lateral lumbo-sacral spine in supine position collected from CEMA center in Beirut, Lebanon: after obtaining an IRB approval and ethical clearance from the center. Taking it as retrospective was for many reasons for example avoiding ethical issues like patient irradiation and the high cost of the examination. The 152 radiographs were collected on June 2020 as images on a CD. Each image contains patient's records including age and gender. The aim of using one source of data was to increase the accuracy and narrowing the bias in the data, since using the same device and protocol contributes to better homogeneity in the results.

The following inclusion and exclusion criteria were used to filtrate the data (Table 1).

TABLE I: THE ELIGIBILITY CRITERIA FOR THE PARTICIPANTS

\begin{tabular}{cc}
\multicolumn{2}{c}{ TABLE I: THE ELIGIBILITY CRITERIA FOR THE PARTICIPANTS } \\
\hline Inclusion Criteria & \multicolumn{1}{c}{ Exclusion Criteria } \\
\hline & $\begin{array}{l}\text { Incomplete records (age or } \\
\text { gender not recorded) }\end{array}$ \\
& - Poor resolution/quality \\
& radiographs \\
- Lebanese nationality & - Radiographs with spinal \\
- Age> 18 years & abnormality \\
- Normal radiographs* & (anterolisthesis, abnormal \\
- Age and gender must & curvature, sacrum in \\
be recorded & abnormal position) \\
& - Patients $<18$ years (to \\
& assure that only those who \\
& have reached spinal \\
& maturity are studied) \\
\hline The criteria for normal radiographs were: & \\
1. The spine must include 5 lumbar and 5 sacral vertebrae. \\
2. The height of vertebrae from L1 to L5 should increase progressively \\
or remain the same.
\end{tabular}

3. The lumbar curvature should be anteriorly convex with a concave curve in the sacral region.

4. The intervertebral disks increase progressively in thickness from L1 to L5.

5. Absence of abnormality in the lumbo-sacral spine [10.]

Statistical analysis was done using SPSS version 20.0 (Chicago, USA). Quantitative data were expressed as mean and standard deviation. Comparison of quantitative measurements was done using Sample t-test and ANOVA test. Statistical significance was set at $p$ value $<0.05$.

\section{B. Measurement of Lumbo-sacral Angle}

The steps of the LSA method are (Fig. 1):

a) Over the plane of the superior margin of the sacral vertebra, a straight line is drawn.

b) A horizontal line is then drawn to form the lumbo-sacral angle.

c) The LSA formed can be measured using a protractor; in this study a software called "ImageJ" was used to measure it, which is an open source image processing program designed for scientific multidimensional images.

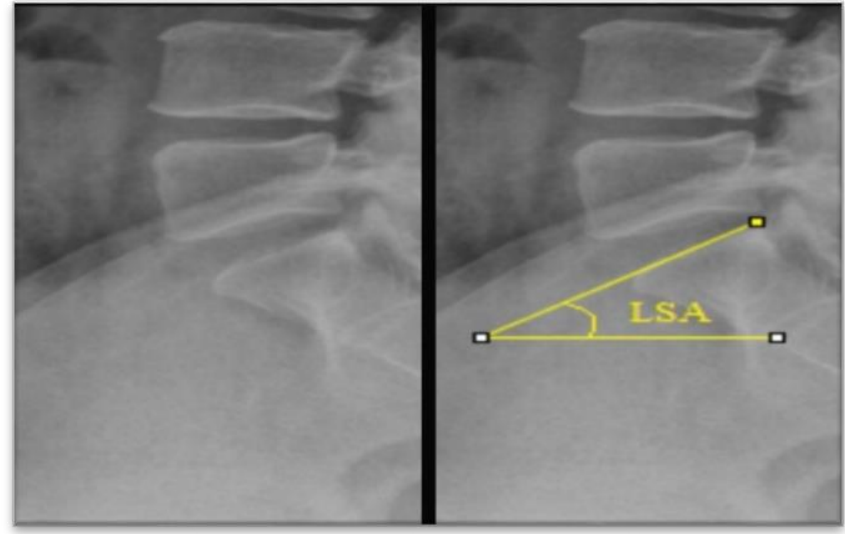

a)

b)

Fig. 1. (a) Radiograph of normal lateral lumbosacral spine (b) measurement lines for the normal lumbosacral angle.

\section{RESUltS AND STATISTICAL ANALYSIS}

In this chapter we intend to show the results obtained after analyzing the data. LSA and the derivative method means and standard deviations for the Lebanese population are calculated using SPSS.

\section{A. Data Selection and Distribution}

\section{Filtration of data}

Out of the 152 radiographs collected, 24 were excluded (as shown in Fig. 2). The reasons of exclusion are incomplete records (no gender or age), abnormal radiographs (pathologies of spine or abnormal shape of vertebrae) and duplicated file (same image for the same subject is repeated twice). The radiographs of 128 subjects who met the inclusion criteria were analyzed. 


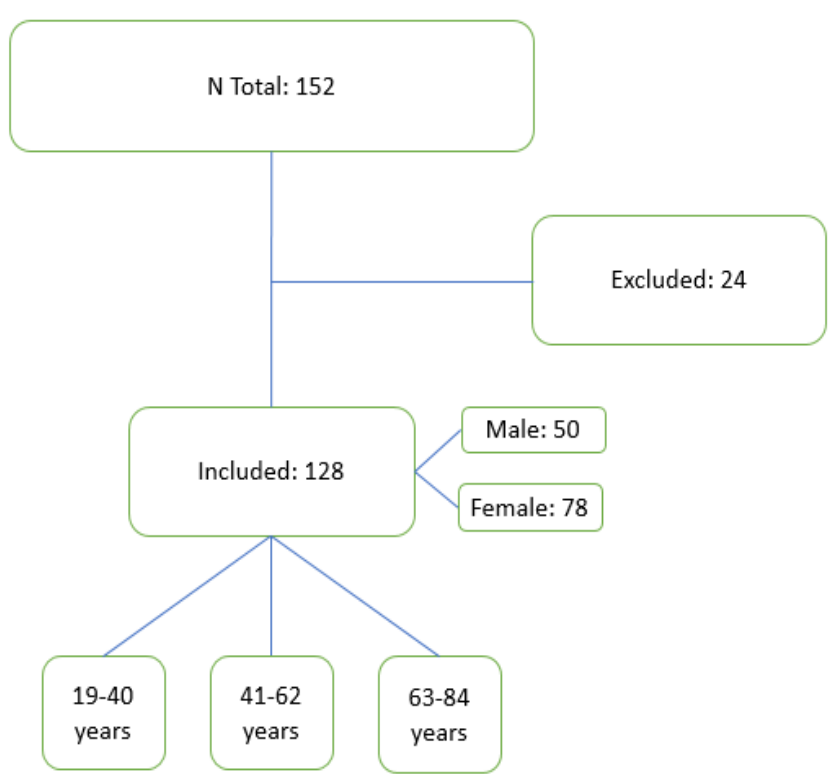

Fig. 2. Flow chart showing the selection and filtration of data.

\section{Distribution of data}

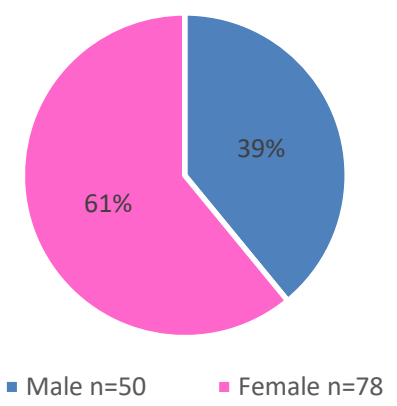

Fig. 3. Pie chart of the distribution of subjects according to gender.

Among the 128 participants, there were 50 (39\%) males and $78(61 \%)$ females (as shown in Fig. 3).

The mean value of age was 49 years with +/- 17.4 SD (age ranged between 19 and 84 years).

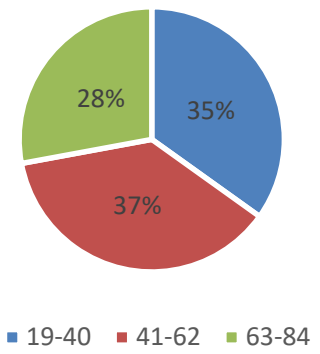

Fig. 4. Pie chart of the distribution according to the age groups.

As shown in Fig. 4, the age was divided into three groups: $1^{\text {st }}$ group: $19-40$ years which compromise $38 \%$ of the population, $2^{\text {nd }}$ group: $41-62$ years $(37 \%)$ and $3^{\text {rd }}$ group: $63-$ 84 years $(28 \%)$.

The mean value of LSA is $38.98+/-9.9$ with a min 15.70 and max 64.20.

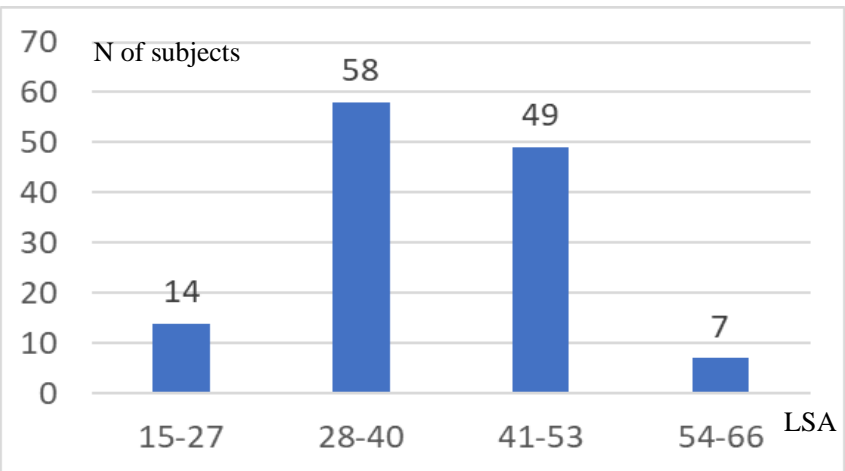

Fig. 5. Bar chart of subjects' distribution according to LSA.

The results in Fig. 5 show that only 7 participants out of 128 had a lumbo-sacral angle between 54-66. In addition, only 14 had it between $15-27$. Whereas 58 subjects had it between 28-40 and 49 with a range of 41-53.

\section{B. Statistical Tests}

A sample T-test was used to analyze the LSA between gender.

\begin{tabular}{|c|c|c|c|c|c|c|}
\hline \multicolumn{7}{|c|}{ ONE-SAMPLE TEST } \\
\hline & \multicolumn{6}{|c|}{ Test Value $=0$} \\
\hline & \multirow[t]{2}{*}{$\mathrm{T}$} & \multirow[t]{2}{*}{ Df } & \multirow{2}{*}{ Sig. (2-tailed) } & \multirow{2}{*}{$\begin{array}{c}\text { Mean } \\
\text { Difference }\end{array}$} & \multicolumn{2}{|c|}{$\begin{array}{l}\text { 95\% Confidence Interval } \\
\text { of the Difference }\end{array}$} \\
\hline & & & & & Lower & Upper \\
\hline Male & 29.688 & 50 & .000 & 38.93333 & 36.2993 & 41.5674 \\
\hline Female & 33.992 & 78 & .000 & 39.22848 & 36.9310 & 41.5260 \\
\hline
\end{tabular}

The results of Table 2 show that the LSA mean of males $(\mathrm{N}=50)$ is $38.9^{0}$ lower than the females' $(\mathrm{N}=78)$ which is $39.2^{0}$. The difference between the LSA mean of male and female is significant ( $\mathrm{p}$ value less than 0.05 ).

ANOVA test was used to analyze the LSA between the three age groups.

\begin{tabular}{cccccc}
\multicolumn{1}{c}{ TABLE III: ANOVA TEST BETWEEN THE THREE AGE GROUPS } \\
\hline & $\begin{array}{c}\text { Sum of } \\
\text { Squares }\end{array}$ & Df & $\begin{array}{c}\text { Mean } \\
\text { Square }\end{array}$ & F & \multirow{2}{*}{ Sig. } \\
\hline Between Groups & 366.692 & 2 & 183.346 & 1.898 & .154 \\
Within Groups & 12073.194 & 125 & 96.586 & & \\
Total & 12439.886 & 127 & & & \\
\hline
\end{tabular}

The results of Table 3 show no significant difference between the 3 age groups since $p$ value is 0.154 which means there is no correlation between LSA and age.

\section{DISCUSSION}

Lumbar lordosis is the inward curvature made by the wedging of the vertebrae of the lumbar spine [1]. It has been linked to the occurrence of low back pain or functional impairments [2] and the relationship between both has a huge clinical importance since it acts as the base of therapeutic exercises for low back pain treatment and prevention [5].

Ethnicity, age, gender, obesity, posture, activity, muscular strength and flexibility of the spine and lower limbs; all these factors may influence the angle of the lordosis, where some studies did not find any correlation between age, gender and LSA [9].

Ferguson's angle, sacro-horizantal angle, the sacral angle, are different name for the lumbo-sacral angle or LSA which 
is the angle formed between a line across the plane of the superior margin of the sacrum and a horizontal line [11].

The aim of our study is to identify the normal LSA in the Lebanese population, then compare the mean value with other studies to see if there's difference between the races, and finally determine if this angle is affected by the gender or age.

The LSA in our study ranged between $15-64^{\circ}$ with a mean value (SD) of $38.98^{\circ}\left( \pm 9.9^{\circ}\right)$; The SD in our study is high since the age range is wide (19-84 years). The range of LSA is wide and this may explain the difference in the mean angle compared to other studies by Chung HJ et al., Fernand R et al., Kim HS et al., and Middleditch A et al. [13]. The mean value of LSA in our study was significantly higher than the mean value reported by Kim HS et al. [14] of $31.70^{\circ}$ and by Chung HJ et al. [15] $32.40^{\circ}$. However, it was significantly lower than that of Fernand $\mathrm{R}$ et al. [12] $\left(46.50^{\circ}\right)$ and Middleditch A et al. [13] $\left(42.50^{\circ}\right)$. These findings suggest that there is a racial variation in LSA being lower in the Asian and higher in Caucasian population which may be due to the different stature of the various races.

To begin with, there is evidence that the females have greater lumbar lordosis according to the literature [9], [16], [17]. Moreover, in this study there is a significant difference between the LSA of male and female, possibly because females have a larger sacral slope than males [18]. Other studies showed that lumbar lordosis does not differ between the genders. One study by Kalichman et al. [19], evaluated lordosis in a supine position. However, in his study Kalichman did not use Xray nor LSA in the measurement, he used CT Scan and Cobb angle; maybe that is why our results are not compatible with his.

According to Okpala, in a study done retrospectively measuring supine lateral lumbo-sacral radiographs of 100 females and 100 males, aged 15 years and above; the LSA was $44.2^{\circ}\left(10.0^{\circ}\right)$ and there was not a significant difference in gender. These results are not compatible with ours, maybe due to the difference in race since this study by Okpala is done in Nigeria; and as previously stated, race is a factor that may affect the LL as claimed by many authors.

However, our results are similar to many studies; Fernand et al. [12], Gelb et al. [20], Murrie et al. [21], Vialle et al. [22], and Youdas et al. [23], [24] that showed that females have greater lordosis angle than males. As mentioned, this difference might be due to the reason that females have a larger sacral slope than the males and they usually have greater buttock size, that is why they have greater lumbar lordosis. In addition, history of pregnancy could influence LL; females considerably gain weight during pregnancy, go through biomechanical and hormonal changes such as the adaptation of LL possibly due to weak abdominal muscles or postpartum joint laxity; thus, increasing lumbar lordosis.

Furthermore, the commonly held view is that LL decreases with subsequent age-related degenerative changes and spinal problems. However, many studies, by Kalichman et al. [19], Murrie et al. [21], Youdas et al. [23], [24] and Naido [25] did not find any association between lordosis and age. According to our results, the LSA is not affected by age since $p$ value was 0.154 (more than 0.05 ).

A study by Tuzun et al. [26], claimed that lumbar lordosis increases with age; maybe because the age of the subjects of Tuzun's study ranged between 20 and 63 years which is different than our range (19-84 years) and the majority of their patients were women. We already assumed that females have larger lumbar lordosis, that is why there is difference in our results and theirs. Another one done by Amonoo-Kuofi [27], showed that it decreases after the $6^{\text {th }}$ decade; maybe due to degenerative disc disease or increasing kyphosis that pushes the body's center of gravity forward with compensatory straightening of the lumbar spine which causes decreased lordosis.

Okpala's study in 2014, which is a retrospective study of lumbo-sacral angle in normal lateral supine radiographs of 274 Nigerians aged between 15 and 74 years, showed that there is no significant variation of the LSA between the various age groups which is similar to our results. LSA was not affected by age, since at spinal maturity, the development of lumbar lordosis hits a plateau [13], [28].

Another reason is, in our current study and the study done by Okpala, we only included the normal radiographs and excluded the radiographs that did not follow the normal criteria which include: the height of vertebrae from L1 to L5 should increase progressively or remain the same, the intervertebral disks increase progressively in thickness from L1 to L5 and absence of abnormality in the lumbo-sacral spine; therefore, excluding the subjects with disc degenerative disease. While other studies when studied the effect of age and found affecting the LSA, mentioned that the reason behind these changes was due to the degeneration of discs (which was excluded in our study). Therefore, no correlation was found between age and LSA.

\section{LIMITATIONS}

The main limitation in this study, since it was a retrospective study, was the inability to collect more information about each subject including weight, height, address, and profession. The weight and height would be necessary to calculate the BMI thus analyzing if obesity affects the LSA as claimed by many authors. The address is also important to compare the results between the regions for example south and north of Lebanon and see if there is any significant difference which might be due to genetic factors. In addition, the profession or activity are useful since they also might affect the LSA.

Another limitation was the delay in getting the radiographs from the center. The reason behind it was the current situation due to COVID-19, which caused delay in getting the data therefore interruption of the study since there was a mandatory quarantine.

In this study, we tried to make an equation to find a correlation between LSA and age, but it was not applicable since the distribution of the 2 variables wasn't graphically correlated.

\section{CONCLUSION}

In this study, evaluation of lumbar lordosis was done on 128 radiographs in a Lebanese population. The range of the LSA was $15-64^{\circ}$ with a mean value (SD) of $38.98^{\circ}\left( \pm 9.9^{\circ}\right)$. The study demonstrated that lumbar lordosis is affected by race and gender, and the difference between the LSA of female and that of male is significant; with females having a 
greater LSA than males. However, no association was found between age and LSA.

This angle $39.98^{\circ}\left( \pm 9.9^{\circ}\right)$ may form a reference value of lumbar lordosis for physicians, physiotherapists, and researchers in the Lebanese population.

\section{RECOMMENDATIONS}

To be more ideal, this study would have been done prospectively using a greater number of patients distributed on all the Lebanese region not only Beirut. However, if further studies were to be done prospectively, it is recommended to collect more information about each subject including BMI and history of low back pain to analyze if these factors do affect the LSA as claimed by many authors.

\section{REFERENCES}

[1] Been, E., \& Kalichman, L. (2014). Lumbar lordosis. Spine J. doi:10.1016/j.spinee.2013.07.464.

[2] Onyemaechi, N. O. (2016). Evaluation of lumbar angles and thei clinical correlates in a Nigerian population. International journal of research in medical sciences, 4. doi:http://dx.doi.org/10.18203/23206012.ijrms20161753.

[3] Truchon, M. (2001). Determinants of chronic disability related to low back pain: Towards an integrative biopsychosocial model. Disability and Rehabilitation, 23, 758-767. doi:10.1080/09638280110061744.

[4] Burton, A. K., Tillotson, K. M., \& Main, C. J. (1995). Psychosocial predictors of outcome in acute and subchronic low back trouble. Spine 20, 722-728. doi: https://doi.org/10.1097/00007632-19950315000014

[5] Chun, S., Lim, C., Kim, K., Hwang, J., \& Chung, S. (2017, August 17) The relationships between low back pain and lumbar lordosis: a systematic review and meta-analysis. The Spine Journal. doi: 10.1016/j.spinee.2017.04.034.

[6] Demir, M., Gümüsburun, E., Seringec, N., Cicek, M., Ertugrul, R., \& Güneri, B. (2018). Radiographic analysis of the lumbar and sacral region angles in young Turkish adults. Journal of the Pakistan Medical Association, 1212-1216. Retrieved from https://www.researchgate.net/publication/326839656

[7] Vrtovec, T., Pernus , F., \& Likar, B. (2009). A review of methods for quantitative evaluation. European Spine Journal, 18, 593-607. doi:10.1007/s00586-009-0913-0.

[8] Berglund, L., Aasa, B., Michaelson, P., \& Aasa, U. (2017): Sagitta lumbo-pelvic alignment in patients with low back pain and the effects of a high-load lifting exercise and individualized low-load motor control exercises - a randomized controlled trial. The Spine Journal, 18(3), 399-406. doi:10.1016/j.spinee.2017.07.178

[9] Dreischarf, M., Pries, E., Bashkuev, M., Putzier, M., Schmidt, H., 2016. Differences between clinical "snap-shot" and "real-life" assessments of lumbar spine alignment and motion - What is the "real" lumbar lordosis of a human being? J. Biomech. 49, 638-644. https://doi.org/10.1016/j.jbiomech.2016.01.032.

[10] Okpala F. (2014). Measurement of lumbosacral angle in normal radiographs: a retrospective study in southeast Nigeria. Annals of medical and health sciences research, 4(5), 757-762. https://doi.org/10.4103/2141-9248.141548.

[11] Wiltse, L. L., \& Winter, R. B. (1983). Terminology and measurement of spondylolisthesis. The Journal of bone and joint surgery. American volume, 65(6), 768-772.

[12] Fernand, R., Fox, D.E., 1985. Evaluation of Lumbar Lordosis. Spine (Phila. Pa. 1976) 10, 799-803. https://doi.org/10.1097/00007632198511000-00003.

[13] Oliver, J., \& Middleditch, A. (1994). Functional anatomy of the spine In Functional Anatomy of the Spine (pp. 328-328).

[14] Hwang, S. H., Park, S. W., \& Kim, Y. H. (2009). Measurement Comparison about Lumbar Lordosis: Radiography and 3D Motion Capture. (O. Dössel, \& W. C. Schlegel, Eds.) World Congress on Medical Physics and Biomedical Engineering, September 7 - 12, 2009 Munich, Germany. doi:10.1007/978-3-642-03882-2_442.

[15] Kim, H.-J., Chung, S., Kim, S., Shin, H., Lee, J., Kim, S., \& Song, M.Y. (2006). Influences of trunk muscles on lumbar lordosis and sacra angle. European Spine Journal. doi:10.1007/s00586-005-0976-5.
[16] Hay et al., 2015

[17] Youdas, J.W., Hollman, J.H., Krause, D.A., 2006. The effects of gender, age, and body mass index on standing lumbar curvature in persons without current low back pain. Physiother. Theory Pract. 22, 229-237. https://doi.org/10.1080/09593980600927864.

[18] Koumantakis et al., 2016

[19] Kalichman, L., Li, L., Hunter, D. J., \& Been, E. (2011). Association between computed tomography-evaluated lumbar lordosis and features of spinal degeneration, evaluated in supine position. The spine journal: official journal of the North American Spine Society, 11(4), 308-315. https://doi.org/10.1016/j.spinee.2011.02.010.

[20] Gelb, D.E., Lenke, L.G., Bridwell, K.H., Blanke, K., McEnery, K.W., 1995. An analysis of sagittal spinal alignment in 100 asymptomatic middle and older aged volunteers. Spine (Phila. Pa. 1976) 20, 13511358

[21] Murrie, V. L., Dixon, A. K., Hollingworth, W., Wilson, H., \& Doyle, T. A. (2003). Lumbar lordosis: study of patients with and without low back pain. Clinical anatomy (New York, N.Y.), 16(2), 144-147. https://doi.org/10.1002/ca.10114.

[22] Vialle, R., Levassor, N., Rillardon, L., Templier, A., Skalli, W., Guigui, P., 2005. Radiographic analysis of the sagittal alignment and balance of the spine in asymptomatic subjects. J. Bone Jt. Surg. - Ser. A 87 260-267. https://doi.org/10.2106/JBJS.D.02043.

[23] Youdas, J. W., Garrett, T. R., Egan, K. S., \& Therneau, T. M. (2000). Lumbar lordosis and pelvic inclination in adults with chronic low back pain. Physical therapy, 80(3), 261-275.

[24] Youdas, J.W., Garrett, T.R., Harmsen, S., Suman, V.J., Carey, J.R., 1996. Lumbar lordosis and pelvic inclination of asymptomatic adults. Phys. Ther. 76, 1066-1081. https://doi.org/10.1093/ptj/77.4.439.

[25] Naido M., 2008. The evaluation of radiographic measurements of the lumbar spine in young to middle aged Indian females in Durban. Durban, South Africa: Durban University of Technology, 111.

[26] Tüzün, C., Yorulmaz, I., Cindas, A., Vatan, S., 1999. Low back pain and posture. Clin. Rheumatol. 18, 308-312. https://doi.org/10.3760/cma.j.issn.0366-6999.2010.07.014.

[27] Amonoo-Kuofi, H.S., 1992. Changes in the lumbosacral angle, sacral inclination and the curvature of the lumbar spine during aging. Acta Anat. (Basel) 145, 373-377.

[28] Chernukha, K. V., Daffner, R. H., \& Reigel, D. H. (1998). Lumbar lordosis measurement: a new method versus Cobb technique. Spine, 23(1), 74-79.

[29] Alexander, C. E., \& Dulebohn., S. C. (2017). StatPearls: Lumbosacra Radiculopathy. PubMed. Retrieved from https://www.ncbi.nlm.nih.gov/books/NBK430837/.

[30] Ayad, C. E., Wahby, D. M.-A., Abdalla, E. A., \& Kajoak, S. A. (2013) Evaluation of Lumber Lordotic Angle in Patients with Intervertebral Disc Prolapse using Cobb's Method. Global Journal of Medical Research Interdisciplinary, 13(7)

[31] Bogduk, N. (1991). The lumbar disc and low back pain. Neurosurgery Clinics of North America, 2(4), 791-806.

[32] Bogduk, N. (2005). Clinical anatomy of the lumbar spine and sacrum. Elsevier Health Sciences.

[33] Burdett, R. G., Brown, K. E., \& Fall, M. P. (1986). Reliability and validity of four instruments for measuring lumbar spine and pelvic positions. Physical therapy, 66(5), 677-684

[34] Dehghan, F., Haerian, B.S., Muniandy, S., Yusof, A., Dragoo, J.L., Salleh, N., 2014. The effect of relaxin on the musculoskeletal system. Scand. J. Med. Sci. Sport. 24, 220-229. https://doi.org/10.1111/sms.12149.

[35] Dreischarf, M., Albiol, L., Rohlmann, A., Pries, E., Bashkuev, M., Zander, T., Schmidt, H. (2014). Age-Related Loss of Lumbar Spinal Lordosis and Mobility - A Study of 323 Asymptomatic Volunteers. PLOS ONE, 9(12). doi:10.1371/journal.pone.0116186.

[36] Evcik, D., \& Yücel, A. (2003). Lumbar lordosis in acute and chronic low back pain patients. Rheumatology International, 23(4), 163-165.

[37] Gierthmühlen, J., Greinacher, J., Höper, J., Oberlojer, V., Lankes, M., Traulsen, F., Baron, R. (2017). Sensory symptoms in low back painhow do they matter? Current Medical Research and Opinion.

[38] Gilbert, J. W., Wheeler, G. R., Storey, B. B., Mick, G. E., Herder, S L., Richardson, G., Martinb, J. C. (2009). Lumbar magnetic resonance imaging hypolordosis in symptomatic patients: association with paraspinal muscle spasms. Journal of Chiropractic Medicine. doi 10.1016/j.jcm.2009.05.001

[39] Gilleard, Wendy, L., Brown, 1996. Structure and function of the abdominal muscles in primigravid. J Mark MPhys. Ther. Nurs. Allied Heal. Database pg 76, 750-762.

[40] Ginanneschi, F., Mondelli, M., Piu, P., \& Rossi, A. (2015). Pathophysiology of knee jerk reflex abnormalities in L5 root injury. Functional Neurology. $\quad$ Retrieved from https://www.ncbi.nlm.nih.gov/pmc/articles/PMC4610754/. 
[41] Gordon, R., \& Bloxham, S. (2016). A Systematic Review of the Effects of Exercise and Physical Activity on Non-Specific Chronic Low Back Pain. Healthcare. doi:10.3390/healthcare4020022.

[42] Hacking, C., \& al., A. T. (2013). Cobb angle. Radiopaedia. Retrieved from https://radiopaedia.org/articles/cobb-angle.

[43] Hegmann, K. T. (2016). Low Back Disorders. American College of Occupational and Environmental Medicine.

[44] Hong, J. Y., Suh, S. W., Modi, H. N., Hur, C. Y., Song, H. R., \& Park, J. H. (2010). Reliability analysis for radiographic measures of lumbar lordosis in adult scoliosis: a case-control study comparing 6 methods. European Spine Journal. doi:10.1007/s00586-010-1422-x.

[45] Huang, Y. P., Bruijn, S. M., Lin, J. H., Meijer, O. G., Wu, W. H. Abbasi-Bafghi, H., Dieën, J. H. (2011). Gait adaptations in low back pain patients with lumbar disc herniation: trunk coordination and arm swing. European Spine Journal. doi: 10.1007/s00586-010-1639-8.

[46] Lee, J. H., \& Lee, S.-H. (2017). Does lumbar paraspinal muscles improve after corrective fusion surgery in degenerative flat black? Indian Journal of Orthopaedics. doi:10.4103/0019-5413.201713.

[47] Levine, D. B. (2010). The Hospital for Special Surgery 1955 to 1972 T. Campbell Thompson Serves as Sixth Surgeon-in-Chief 1955-1963 Followed by Robert Lee Patterson, Jr. the Seventh Surgeon-in-Chief 1963-1972. HSS Journal. doi:10.1007/s11420-009-9136-5.

[48] Marnach, M.L., Ramin, K.D., Ramsey, P.S., Song, S.W., Stensland, J.J., An, K.N., 2003. Characterization of the relationship between joint laxity and maternal hormones in pregnancy. Obstet. Gynecol. 101, 331-335. https://doi.org/10.1016/S0029-7844(02)02447-X.

[49] McCarthy, J. J., \& Betz, R. R. (2000). The relationship between tight hamstrings and lumbar hypolordosis in children with cerebral palsy. Spine, 25(2), 211-213. https://doi.org/10.1097/00007632 200001150-00011.

[50] Mehta, L. S., Beckie, T. M., DeVon, H. A., Grines, C. L., Krumholz, H. M., Johnson, M. N., ... \& Wenger, N. K. (2016). Acute myocardial infarction in women: a scientific statement from the American Heart Association. Circulation, CIR-0000000000000351.

[51] Mehta, R. S., Nagrale, S., Dabadghav, R., Rairikar, S., Shayam, A., \& Sancheti, P. (2016). Assessment of Lumbar Lordosis and Lumbar Core Strength in Information Technology Professionals. Asian Spine Journal. doi: 10.4184/asj.2016.10.3.495.

[52] Mirbagheri, S. S., Rahmani-Rasa, A., Farmani, F., Amini, P., \& Nikoo, M. R. (2015). Evaluating kyphosis and lordosis in students by using a flexible ruler and their relationship with severity and frequency of thoracic and lumbar pain. Asian spine journal, 9(3), 416-422. doi: 10.4184/asj.2015.9.3.416.

[53] Mosner, E. A., Bryan, J. M., Stull, M. A., \& Shippee, R. (1989). A comparison of actual and apparent lumbar lordosis in black and white adult females. $\quad$ Spine, 310-314 https://doi.org/10.1097/00007632-198903000-00011.

[54] O’Rahilly, R., Müller, F., Carpenter, S., \& Swenson, R. (2004). Basic human anatomy: a regional study of human structure.

[55] Okpala, F. O. (2016). Normal pediatric lumbar lordosis: Measurement of magnitude and age of maximum development using three radiographic techniques. West African Journal of Radiology, 23(2), 8288. doi: 10.4103/1115-3474.172093.

[56] Purves (2004). Neuroscience: Third Edition. Massachusetts, Sinauer Associates, Inc.

[57] Saladin, K. S. (2007). Human Anatomy. Springer.

[58] Sam, E. M. (2011). Problem Based Neurosurgery. World Scientific.

[59] Shier, D., Butler, J., \& Lewis, R. (2001). Human anatomy and physiology. Boston, MA, USA: McGraw-Hill.

[60] Stagnara, P., De Mauroy, J.C., Dran, G., Gonon, G.P., Costanzo, G. Dimnet, J., Pasquet, A., 1982. Reciprocal angulation of vertebral bodies in a sagittal plane: approach to references for the evaluation of kyphosis and lordosis. Spine (Phila. Pa. 1976) 7, 335-342.

[61] Stone, J., \& Vermeulen, M. (2016). Functional sensory symptoms. Handbook of Clinical Neurology. doi:10.1016/B978-0-12-8017722.00024-2.

[62] Takao S, Sakai T, Sairyo K, et al. (2010) Radiographic comparison between male and female patients with lumbar spondylolysis. J Med Invest 57:133-7.

[63] Tortora, G. J., \& Derrickson, B. (2013). Essentials of anatomy and physiology. Wiley.

[64] Walker, H. K. (1990). Clinical Methods: The History, Physical, and Laboratory Examinations. (3rd ed.).

[66] Yousef, A.M., Hanfy, H.M., Elshamy, F.F., Awad, M.A., Kandil, I.M., 2011. Postural changes during normal pregnancy. J. Am. Sci. 7, $1013-$ 1018. https://doi.org/10.1017/CBO9781107415324.004

[67] Zaproudina, N., Ming, Z., \& Närhi, M. (2015). Sensory and sympathetic disorders in chronic non-specific neck pain. Functional Neurology. doi: 10.11138/FNeur/2015.30.3.165. 